\title{
An Empirical Study on the Impact of Rural E-commerce Development on Rural Residents' Consumption in China
}

\author{
Zhang Nannan ${ }^{1, a}$ \\ ${ }^{1}$ School of Economics and Management, Beijing Jiaotong University, Beijing, China \\ a15120561@bjtu.edu.cn \\ *Zhang Nannan
}

Keywords: Rural e-commerce, Consumption expenditure of rural residents, Internet+.

\begin{abstract}
This article points out that the promotion and popularization of "Internet + " and mobile terminals make rural e-commerce a new way of agricultural development in China. At the same time, the state is constantly introducing new policies from the reform level and financial level to give rural e-commerce strong support. Under this background, this paper makes some analysis and discussion on the development of rural e-commerce, using the methods of literature analysis and empirical analysis, and puts forward some reasonable suggestions on the development of rural e-commerce in the future.
\end{abstract}

\section{Introduction}

Under the influence of "Internet+" in the whole country, the new mode of e-commerce began to penetrate into the countryside, and set off a strong wind of rural e-commerce. Rural e-commerce, shared economy and mobile payment are the three hot spots in the field of internet in 2016.

In recent years, agricultural products become one of the online commodities on the network platform. But overall, the current rural e-commerce construction in China is still in the exploratory stage. Compared with other rural e-commerce in the more mature countries, there is still a large gap. In 2015, Li Keqiang, premier of the state Council, presides over the standing meeting of the state Council. Which declared that accelerate the development of e-commerce in rural areasand, improve the development environment of rural e-commerce, improve the transportation, information, production distribution, cold chain and other related facilities and develop third-party distribution and so on, to improve the efficiency of circulation.

In the background of national policy opening and mobile internet, this paper uses literature analysis method and empirical analysis method to analyze the impact of the development of rural e-commerce on rural residents consumption. And the paper will give some policy suggestions, which has important theoretical and practical significance for the new mode of agricultural electronic commerce and the rural economic development in the future.

\section{Literature review}

Foreign scholars in the study of rural e-commerce started earlier. There begin to have more in-depth and authoritative research from 2001. These studies mainly focused on the rural e-commerce development model, the rural e-commerce impact on the logistics industry and the impact of rural e-commerce development factors analysis. B2B mode is widely concerned by foreign scholars in the development mode of rural e-commerce. In 2001, Roux and o' keeffe qualitatively analyzed the influence factors of the development of B2B e-commerce in agriculture. They believed that not only the pricing of agricultural products would affect the development of e-commerce, but also the existence and profitability of the third-party enterprises played a crucial role. Janom and zakaria made a quantitative study on the development of e-commerce performance of SMEs in 2003.

Domestic research and attention to rural e-commerce began in 2012. From the research content, at this stage, the main concerns of the literature are as follows: 1.the status and development of rural e-commerce.Hu Tianshi and Fu Tiexin (2005) believe that the agricultural e-commerce model is a 
revolutionary change to the traditional agricultural economy. 2.the development of rural e-commerce in different areas of the model and case study. Zheng Yaqin and Li Qi (2007) believe that the integration of network information chain is the premise of developing agricultural e-commerce. 3.online shopping preferences and so on.He Dehua et al. (2014) and Wu Ziqiang (2015) analyze the influencing factors of the consumers' willingness to purchase fresh agricultural products online through an empirical analysis.

\section{Index selection and model construction}

\subsection{Index selection and data source}

This paper mainly studies the impact of rural e-commerce on rural residents consumption. Considering the indirect and operability of data, this paper adopts rural internet population (RN) and rural internet penetration (RP) as two indicators in order to reflect the development of rural e-commerce more clearly. Rural residents consumption uses the national rural residents per capita consumption expenditure (RC) indicators. Due to the limitations of rural internet development, the relevant available data are less, so the sample range is selected from 2006 to 2016.

The number of rural internet users and rural internet penetration are all originated from the China network retail market data monitoring report. The data of per capita consumption expenditure of rural residents in China are from the statistical yearbook of China in 2007-2016.

Due to the difference between the statistical units results in a large gap between the data, so each group of data is logarithmic transformed, the processed indicators are: $L N R N, L N R P$ and LNRC. So that they can be intuitively displayed in the same chart. Through the collection and collation of a large amount of data, this paper obtains the descriptive data of rural e-commerce development and rural residents per capita consumption expenditure as shown in figure 1. It can be seen that the rural internet penetration and the number of internet users both are increasing. Overall it seems that from 2008 , the growth rate has been reduced, but still in the upward trend.

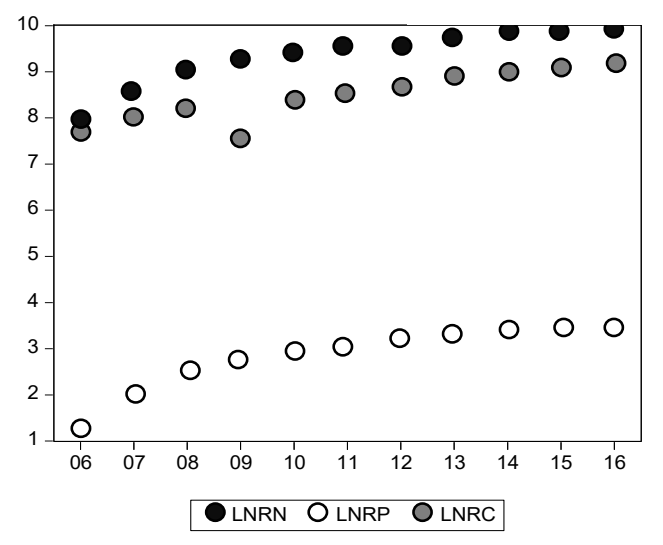

Fig. 1. The number of rural netizens, rural internet popularization rate, and the change of per capita consumption expenditure trend of rural residents

It can be known from the collected data, the number of urban and rural internet users has been growing, but the number of urban internet users is significantly more than rural netizens. And the proportion of rural internet users in China is at about $28 \%$ in recent years. The per capita consumption expenditure of rural residents in China has also increased in the past ten years, which shows that China has made some achievements in supporting the development of rural industry and promoting rural economic growth.

\subsection{Model}

In order to get the impact of the number of rural internet users and rural internet penetration rate on the consumption of rural residents, the empirical analysis in this paper adopts panel data analysis method. The panel data is also called " parallel data ", which refers to taking multiple sections on the 
time series, and selecting sample data from the sample observations at the same time. Its advantage is that it can overcome the Multiple in time series analysis. It also can provide more information, more changes, less multicollinearity, more degrees of freedom and higher estimation efficiency. The general form of the panel data model is as follows:

$$
y_{i t}=\sum \beta_{i t} x_{i t}+u_{i t} .
$$

Where $i=1,2, \ldots n$, represents $n$ individuals. $T=1,2, \ldots, t$, represents the known $t$ time point. $y_{i t}$ is the observation value of the interpreted variable to the individual $i$ in $t . \beta_{i t}$ is the observation value of the kth non-random explanatory variable for individual $i . x_{i t}$ is the parameter to be estimated. $u_{i t}$ is a random error term.

\section{Empirical analysis}

\subsection{Unit root test}

Unit root test is more effective than time series data in the analysis of panel data model. There are many methods to test unit root, which can be used in the panel unit root test of LLC, IPS, Breintung, ADF-fisher and PP-fisher. In this paper, we choose the ADF test method to measure the rural e-commerce development indicators, rural per capita consumption expenditure variables and their first order difference whether there exist unit roots. If they all reject the original hypothesis of unit root, it can be considered that the sequence is stable, and vice versa. Table 1 is the statistical result of the unit root test for each variable by eviews, and the value in the table is the "p" of the test result.

Table 1. Unit root test result

\begin{tabular}{ccccccc}
\hline Indicators & $\mathrm{RN}$ & $\mathrm{RP}$ & $\mathrm{RC}$ & LNRN & LNRP & LNRC \\
\hline $\mathrm{ADF}$ & 0.0335 & 0.0847 & 0.9498 & 0.0449 & 0.0045 & 0.0266 \\
$(\mathrm{P})$ & & & & $* *$ & $* * *$ & $* *$ \\
\hline
\end{tabular}

Note: the lag length is automatically selected according to the SCI rule. * represents a significant level of $10 \%$, ** indicates a significant level of $5 \%, * * *$ indicates a significant level of $1 \%$.

\subsection{Cointegration test}

Cointegration test is to determine whether a set of linear combinations of a set of non-stationary sequences have a stable equilibrium relationship. In the past, we can see all the first order difference of all sequences is stationary, so we continue to carry out cointegration test. The three sequences of $L N R N, L N R P$ and $L N R C$ are regressed by ordinary least square (ols) method, the results are as follows:

$$
L N R C=114.5117-15.9680 * L N R N+15.1527 * L N R P .
$$

Then, use the above regression equation to find the residual sequence, and the residual sequence is named $E$. Next step is testing the residual sequence. If the residual $E$ sequence is stationary, it is considered that the three sequences have cointegration relationship. The test results are as follows:

Table 2. The unit root test result of the residual sequence

\begin{tabular}{cccccc}
\hline Indicator & $\begin{array}{c}\mathrm{ADF} \\
(\mathrm{P})\end{array}$ & $1 \%$ & $5 \%$ & $10 \%$ & Smooth/not \\
\hline $\mathrm{E}$ & $\begin{array}{l}-4.6220 \\
(0.0004)\end{array}$ & -2.8167 & -1.9823 & -1.6011 & $\mathrm{Y} * * *$ \\
\hline
\end{tabular}

Note: the lag length is automatically selected according to the SCI rule. * represents a significant level of $10 \%$, ** indicates a significant level of $5 \%, * * *$ indicates a significant level of $1 \%$.

According to the above results, there is a co-integration relationship between $L N R C$ and $L N R N$ and $L N R P$. It means there is a long-term equilibrium relationship between the rural per capita consumption expenditure and the development of rural e-commerce in this paper. However, from the results, the number of rural rural netizens and the impact of rural network popularity on rural 
residents' consumption seems to be not in line with the actual (the increase in the number of rural internet users has caused the rural per capita consumption level), which may be related to the insufficiency of relevant statistical data and the selection of the model.

\section{Conclusions}

Through the empirical analysis of rural e-commerce development and rural residents per capita consumption expenditure, the results show that rural residents per capita consumption in China is affected by the number of rural internet users and rural internet penetration. The number of rural internet users has negative impact on per capita consumption, while rural internet penetration has a positive impact on per capita consumption expenditure of rural residents. However, because of the late start of rural e - commerce, the data samples can be queried at this stage, so the empirical analysis is lack of some convincing. This paper makes a certain basic and theoretical contribution to the future research in this area. In view of the above analysis, this paper puts forward the following countermeasures to promote the development of rural e-commerce in China: 1. Regard strengthening the infrastructure construction of rural e-commerce as the basic of the development of rural e-commerce.2. Strengthen application of network knowledge education to enhance the applicability of the equipment. 3.Pay attention to the important role of logistics industry in the development of rural e-commerce. This paper mainly studies the impact of rural residents' acceptance and application on their living consumption in the process of rural electric commerce development. Logistics in the development of rural e-commerce has not only achieved the online and offline links, but also further promoted the popularity of e-commerce in rural areas because of the continuous improvement of logistics services.

\section{References}

[1] J. J. Liu, Farmer cooperatives electricity business model of China's rural e-commerce development viable path, Int. J. agricultural research, 2013

[2] Z. Q. Wu, An Empirical Study on the Influencing Factors of Online Shopping Willingness of Fresh Agricultural Products, Int. J. Statistics \& Decision, vol.20, 2015.

[3] D. H. He, X. Y. Han, and Y. Z. Li, Study on the Purchasing Willingness of E-commerce Consumers of Fresh Agricultural Products, Int. J. Journal of Northwest Sci-Tech University of Agriculture and Forestry, 2014.

[4] J. Song, Research on the Impact of Broadband China Plan on the Development Potential of Rural Electricity and Commercial Logistics Market, Int. J. Logistics Technology, vol. 5, 2014.

[5] Y. C. Zhang, Rural electric business to accelerate the development of the logistics industry to bring the impact, Int. J. Logistics technology and application, vol.10, 2015.

[6] Barcarin,E;Madeire,R.M. and Mdeiros, C.B. ,Contract E-negotiation in Agricultural Supply Chains, International Tournal of Electronic Commerce, vol.12, pp. 1-98, 2008.

[7] Janom, N. and Zakaria, M . S. ,The Development of B2b E-commerce Readiness Assessnebt Model for SMEs: Identification of Barriers Using AHP Method, International Journal of Information Science and Management, vol.2, pp. 61-75, 2003.

[8] O'Keeffe, M.:Myths and Realities of E-commerce in the Perishable Foods Industries : Unleashing the Power of Reputation and Relationship Assets,Supply Chain Management: An International Journal,6(1):12-15,2001 